\title{
Cytinus hypocistis (L.) L.: Optimised heat/ultrasound-assisted extraction of tannins by response surface methodology
}

\author{
Ana Rita Silva ${ }^{\text {a,b }}$, José Pinela ${ }^{\text {a, }}$, Pablo A. García ${ }^{\mathrm{b}}$, Isabel C.F.R. Ferreira ${ }^{\mathrm{a}}$, Lillian Barros ${ }^{\mathrm{a}, *}$ \\ ${ }^{a}$ Centro de Investigação de Montanha (CIMO), Instituto Politécnico de Bragança, Campus de Santa Apolónia, 5300-253 Bragança, Portugal, Spain \\ ${ }^{\mathrm{b}}$ Departamento de Ciencias Farmacéuticas. Facultad de Farmacia, CIETUS-IBSAL, Universidad de Salamanca, 37007 Salamanca, España, Spain
}

\section{A R T I C L E I N F O}

\section{Keywords:}

Parasitic plant

Hydrolysable tannins

Heat/Ultrasound-assisted extraction

Extraction optimisation

Hydroethanolic solvent

\begin{abstract}
A B S T R A C T
Tannins are a class of phenolic compounds commonly found in plants and studied for their bioactive and inhibitory enzyme properties. Cytinus hypocistis (L.) L. is a wild edible parasitic plant whose biological properties have been correlated with its high tannin content. Thus, studying the extraction of tannins from C. hypocistis will give comprehensive clues to enhance the recovery of these high added-value bioactive compounds. The present work applied Response Surface Methodology (RSM) to optimise tannins extraction using Heat-Assisted (HAE) and Ultrasound-Assisted (UAE) methods. Two three-factor Rotatable Central Composite Designs were used to assess the linear, quadratic, and interaction effects of the independent variables on the target responses. The obtained results from both extraction systems revealed high ethanol percentages as the critical factor in increasing tannin content. The optimum global processing conditions predicted by the polynomial models were 95.1 $\mathrm{min}, 46.4{ }^{\circ} \mathrm{C}$, and $74.3 \%$ ethanol for HAE; and $18.7 \mathrm{~min}, 327.4 \mathrm{~W}$, and $69.3 \%$ ethanol for UAE. Following these conditions, $200 \mathrm{mg}$ and $178 \mathrm{mg}$ of total tannins per $\mathrm{g}$ of extract were recovered using HAE and UAE, correspondingly. Although HAE presented a higher final response, the UAE stood out as a time-saving technique.
\end{abstract}

\section{Introduction}

Tannins are one of the most abundant components extracted from plant biomass [1]. The first known application of tannin-rich plant material dates back to the Mediterranean region approximately 1500 BCE, where they were used to prevent animal skin degradation [2]. The word 'tannin' was later introduced (1976) to describe the plant extract substances that can convert animal skin into leather [3].

Tannins classification is full of misunderstanding, inaccurate interpretations, and alterations caused by improvements in the field. Some tanning substances cannot be called tannins, and on the other hand, many tannins do not possess tanning properties but are included within the class due to their structural characteristics and chemical properties [4]. Tannins are broadly classified into two groups, hydrolysable and condensed $[5,6]$. Hydrolysable tannins are esters of gallic acid (gallotannins) and ellagic acid (ellagitannins) with a sugar core. In comparison, the non-hydrolysable oligomeric and polymeric proanthocyanidins, known as condensed tannins, do not possess a sugar core and are comprised of flavonoid units (flavan-3-ol or flavan-3,4-diol) [4,6]. The understanding that many tannins could be hydrolytically fractionated into their components led to their classification as hydrolysable.
Nonetheless, some ellagitannins cannot be hydrolytically fractionated [4]. Additionally to their characteristic structural element hexahydroxydiphenoyl (HHDP), they present a C-C coupling of their catechin unit with the glycosidic part, which makes them only partially hydrolysable and contributed to their classification as 'non-classified tannins' $[7,8]$. The terms 'complex tannins' and flavanoellagitannins were established to properly group these 'non-classified tannins'. According to Khanbabaee and Ree, the examples mentioned above indicate that dividing tannins into two groups cannot do justice to their structural diversity [4]. Therefore, some authors classify tannins into four groups based on their structural characteristics, namely: ellagitannins, gallotannins, complex tannins, and condensed tannins (Fig. A.1 in supplementary material) [4,9-11]. Ellagitannins correspond to those tannins in which at least two galloyl units are $\mathrm{C}-\mathrm{C}$ coupled and do not contain a glycosidically linked catechin unit; gallotannins include all tannins in which galloyl units or their meta-depsidic derivatives are connected to different polyol-, catechin-, or triterpenoid units; complex tannins are tannins in which a catechin unit is bound glycosidically to a gallotannin or an ellagitannin unit; and condensed tannins are all oligomeric and polymeric proanthocyanidins formed by the linkage of a C-4 of one catechin with C-8 or C- 6 of the next monomeric catechin [4].

\footnotetext{
* Corresponding authors.

E-mail addresses: jpinela@ipb.pt (J. Pinela), lillian@ipb.pt (L. Barros).
} 
Tannin's biosynthesis is usually associated with defensive responses against herbivores, pathogens, and UV radiation. These compounds are stored in vacuoles and can be found in a wide variety of plants. Condensed tannins are significantly more abundant than hydrolysable tannins, which are only present in a few species [12]. Cytinus hypocistis (L.) L. is a wild edible parasitic plant on various Cistaceae family members, whose biological properties (antioxidant, anti-tyrosinase, anti-inflammatory, and antimicrobial) have been correlated with its high content in hydrolysable tannins. Thus, studying the optimisation of hydrolysable tannins extraction from $C$. hypocistis will give comprehensive clues for the enhanced recovery of these high added-value bioactive compounds and their potential cosmeceutical applications [13]. The present work aimed at assessing and optimise the extraction of hydrolysable tannins from $C$. hypocistis using both a conventional (HeatAssisted Extraction - HAE) and a sustainable extraction method (Ultrasound-Assisted Extraction - UAE). During conventional extraction, plant material is homogenised and soaked in a solvent (or mixture of solvents), often under constant stirring and with or without heat treatment [14]. These techniques are very simple but present some disadvantages, such as poor efficiency or high solvent consumption. Contrarily, more sustainable non-conventional extraction techniques utilise ultrasounds, microwaves, supercritical fluids, and electrical/ mechanical technologies to improve the extraction efficiency and/or selectivity of a wide range of bioactives [15-17]. During UAE, different ultrasonic cavitation intensities are used to create micro-bubbles inside the solvent for a certain period of time; these bubbles expand and collapse, causing vibrations and breaking cell walls favouring the penetration of solvents and consequent release of target compounds [12].

The solubility of tannins is variable; it depends on the target compound, and therefore, solvents with different relative polarities, such as water, ethanol, acetone, and/or methanol, are usually selected. Condensed tannins, for example, have limited solubility in polar organic solvents, whereas ethanol and water are the two generally used solvents for the extraction of hydrolysable tannins [12,18]. Solvents are key factors to determine the class of compounds extracted; in contrast, other independent variables, such as solvent ratio, temperature, pressure, power, and extraction time, affect compounds extraction yield and stability $[19,20]$. These independent variables should be combined in experimental designs with an appropriate optimisation method, such as the Response Surface Methodology (RSM). Contrarily to one-factor-at-atime approaches, RSM describes the relationship between independent variables and one or more dependent (or response) variables, allowing to determine interaction effects and optimise processes using a low number of experimental runs $[19,21]$. In this study, two Rotatable Central Composite Designs (RCCDs) were applied to assess the linear, quadratic, and interaction effects of the independent variables on the target responses (extract weight and tannins content). A Central Composite Design (CCD) is called rotatable if, at any point, the variance of the predicted response only depends on the distance of the point from the centre point of the design. All points at the same radial distance (r) from the centre point have the same magnitude of prediction error; the proper choice of $\alpha$ values is responsible for this uniformity [22].

Therefore, this study was performed to investigate and compare the suitability of HAE and UAE for extracting seven hydrolysable tannins from C. hypocistis by implementing a RCCD design coupled with RSM for processes optimisation.

\section{Material and methods}

\subsection{Chemicals and standards}

High-Performance Liquid Chromatography (HPLC)-grade acetonitrile (99.9\%) was acquired from Fisher Scientific (Lisbon, Portugal) and formic acid from Panreac (Barcelona, Spain). Phenolic compound standards (gallic acid and ellagic acid) were purchased from
Extrasynthese (Genay, France). All other chemicals were of analytical grade and purchased from common sources. Water was treated employing a Milli-Q water purification system (TGI Pure Water Systems, Greenville, SC, USA).

\subsection{Plant material}

Cytinus hypocistis (L.) L. subsp. macranthus Wettst plants were collected in July 2019 from the host species Halimium lasianthum (Lam.) Spach subsp. alyssoides (Lam.) Greuter at three locations in Castro Daire, Portugal. Plant identification, characterisation, and preparation were conducted as previously described [23]. After lyophilisation (Zirbus Technonoly VaCo 10-II, Bad Grund, Germany), plant specimens were milled to a fine powder ( $\sim 40$ mesh) and stored at room temperature for further analysis.

\subsection{Experimental design}

Two three-factor RCCD designs were implemented to optimise the extraction of tannins from $C$. hypocistis. The two designs (for HAE and UAE) investigated the relationship between the independent variables $X_{1}$ [ $t$ (min): time], $X_{2}\left[T\left({ }^{\circ} \mathrm{C}\right)\right.$ : temperature or $P(\mathrm{~W})$ : ultrasonic power], and $X_{3}$ [S (\%): solvent ratio (\% of ethanol/water, $\left.v / v\right)$ ], and the dependent variables $Y_{1}$ to $Y_{9}$. These independent variables as well as the ranges in which they were varied (Table 1), were selected based on previous optimisation studies and research group experience $[5,12,14,24-29]$. Considering the selected design for a three-factor experimentation $\left(X_{1}, X_{2}\right.$, and $\left.X_{3}\right)$, eight $\left(2^{\mathrm{k}}=2^{3}\right)$ factorial points, six axial or star points $(2 \times 3)$, and six centre points were chosen. The software Design-Expert v11 (Stat-Ease, Inc., Minneapolis, MN, USA) was used to generate the 20 experimental runs by entering the factor ranges in terms of alphas $\left(\alpha=1.68\right.$ ), where the $\alpha$ value was $(8)^{1 / 4}=1.68$. Each variable to be optimised was coded at five levels: $-1.68,-1,0,+1$, and + 1.68 . The correspondence between coded and natural variables is presented in Table 1.

\subsection{Extraction methods}

For HAE, $400 \mathrm{mg}$ of plant material was mixed with $20 \mathrm{~mL}$ of solvent (hydroethanolic solution at different concentrations, 0-100\%). The vial containing the mixture was then sealed and positioned in a thermostatic water bath with continuous magnetic stirring. The powdered samples were extracted according to different time $(t)$ and temperature $(T)$ intervals, 5 to $120 \mathrm{~min}$ and 25 to $95^{\circ} \mathrm{C}$, respectively. For UAE, $1 \mathrm{~g}$ of plant material was mixed with $50 \mathrm{~mL}$ of solvent (hydroethanolic solution at different concentrations, $0-100 \%)$. The beaker containing the mixture was processed with an ultrasonic system (CY-500, Optic Ivymen System, Barcelona, Spain) equipped with a titanium probe. Samples were treated using different ultrasonic power ( $P$ : 5-500 W; at $20 \mathrm{kHz}$ frequency) and time ( $t$ : 2-45 $\mathrm{min}$ ) intervals; the temperature was maintained constant (ice was used to prevent samples heating). Both extraction methods, HAE and UAE, were performed with a solid/liquid ratio of $20 \mathrm{~g} / \mathrm{L}$. The RSM designs comprised 20 experimental runs (performed in randomised

\section{Table 1}

Natural and coded values of the independent variables applied in the RCCD design for the optimisation of tannins extraction from C. hypocistis using RSM.

\begin{tabular}{|c|c|c|c|c|c|c|}
\hline \multirow[t]{3}{*}{ Coded values } & \multicolumn{6}{|c|}{ Natural values } \\
\hline & \multicolumn{3}{|l|}{ HAE } & \multicolumn{3}{|l|}{ UAE } \\
\hline & $t(\min )$ & $T\left({ }^{\circ} \mathrm{C}\right)$ & $S(\%)$ & $t(\min )$ & $P(\mathrm{~W})$ & $S(\%)$ \\
\hline-1.68 & 5 & 25 & 0 & 2 & 5 & 0 \\
\hline-1 & 28 & 39 & 20 & 11 & 106 & 20 \\
\hline 0 & 62.5 & 60 & 50 & 23.5 & 253 & 50 \\
\hline+1 & 97 & 81 & 80 & 36 & 400 & 80 \\
\hline+1.68 & 120 & 95 & 100 & 45 & 500 & 100 \\
\hline
\end{tabular}


order) planned as mentioned above. After extraction, samples were centrifuged at $3000 \mathrm{~g}$ for $10 \mathrm{~min}$ and filtered through Whatman paper no 4. Two millilitres of each filtrate were added to ceramic crucibles and used to determine the extraction yield (extract dry weight or extracted solids, $\%, w / w$ ) by removing the solvent in an oven at $100{ }^{\circ} \mathrm{C}$ until constant weight was achieved $(\sim 24 \mathrm{~h})$; the remaining filtrate was frozen and lyophilised for total and individual tannin quantification.

\subsection{Tannin's quantification}

Extracts were dissolved in water/ethanol $(80: 20, v / v)$ at a $20 \mathrm{mg} / \mathrm{mL}$ final concentration and filtered through a $0.22 \mu \mathrm{m}$ nylon disposable filter. As formerly described, the seven major tannins were analysed by HPLC-DAD-ESI/MS ${ }^{n}$ (Dionex Ultimate 3000 UPLC, Thermo Scientific, San Jose, CA, USA). Tannins were characterised according to their UV spectra, fragmentation pattern, retention times, and comparison with available standards $[13,30]$. For quantification, seven-level calibration curves were obtained from the most similar commercially available standard compounds, namely gallic acid $\left(\mathrm{y}=131538 \mathrm{x}+292163 ; r^{2}=\right.$ 0.9998; LOD $=0.68 \mu \mathrm{g} / \mathrm{mL} ; \mathrm{LOQ}=1.61 \mu \mathrm{g} / \mathrm{mL})$ and ellagic acid $(\mathrm{y}=$ $26719 \mathrm{x}-317255 ; r^{2}=0.9996 ; \mathrm{LOD}=0.10 \mu \mathrm{g} / \mathrm{mL}$, LOQ $=0.48 \mu \mathrm{g} /$ $\mathrm{mL})$. The results were expressed in $\mathrm{mg}$ tannins per $\mathrm{g}$ of extract (E).

\subsection{Extraction process modelling and statistical analysis}

The responses were expressed in the form of nine dependent variables $(Y)$ and used to optimise the recovery of tannins from $C$. hypocistis: $Y_{1}$, extraction yield (extract dry weight or extracted solids, $\%, w / w$ ); $Y_{2}$, $\mathrm{mg}$ of tetragalloyl-glucoside II per $\mathrm{g}$ of extract (E); $Y_{3}, \mathrm{mg}$ of tetragalloylglucoside III per $\mathrm{g}$ of $\mathrm{E} ; Y_{4}, \mathrm{mg}$ of pentagalloyl-glucoside per $\mathrm{g}$ of $\mathrm{E} ; Y_{5}$, $\mathrm{mg}$ of galloyl-bis-HHDP-glucose II per $\mathrm{g}$ of $\mathrm{E} ; Y_{6}, \mathrm{mg}$ of digalloyl-bisHHDP-glucose II per $\mathrm{g}$ of E; $Y_{7}, \mathrm{mg}$ of trigalloyl-bis-HHDP-glucose I per $\mathrm{g}$ of $\mathrm{E} ; Y_{8}, \mathrm{mg}$ of trigalloyl-bis-HHDP-glucose II per $\mathrm{g}$ of $\mathrm{E}$; and $Y_{9}, \mathrm{mg}$ of tannins (total) per $g$ of $\mathrm{E}$. As extensively described by Rocha and colleagues [21], fitting procedures, coefficient estimates, and statistical verifications were performed using the software Design-Expert. The ANOVA (analyses of variance) was used to evaluate the significance of the models generated (polynomial equations), as well as the lack-of-fit. The test for statistical significance was performed by calculating the $p$ value from the F-value, acknowledging the significance of $p$-value $<$ 0.05 . Statistically non-significant terms $(p$-value $>0.05$ ) were omitted to simplify the models (except those required to ensure hierarchy). The adequate precision, the coefficient of determination $\left(\mathrm{R}^{2}\right)$, and the adjusted coefficient of determination $\left(\mathrm{R}^{2}\right.$ adj $)$ were used to assess the adequacy of the polynomial equations to the final responses. For adequate precision, which measures signal-to-noise ratio, the value must be $>4$, whereas $R^{2}$ and $R^{2}$ adj must exhibit a value close to 1 , illustrating an agreement between the theoretical and experimental data [31].

\section{Results and discussion}

\subsection{Experimental data obtained with the two RCCDs}

In a previous study [13], a total of 17 phenolic compounds (16 tannins and a catechin) were identified (HPLC-DAD-ESI/MS ${ }^{\mathrm{n}}$ analysis) in this species. The total tannin content, together with the most abundant 7 hydrolysable tannins and the extraction yield, were the selected response variables during the present optimisation work. The HAE and UAE experimental results are presented in Table 2.

The $Y_{1}$ response corresponds to the extraction yield (extract dry weight, $\%, w / w$ ). From the analysis of the experimental results for both methods (Table 2), it is possible to observe that the $\%$ yield and $\%$ of ethanol follow an inverse correlation. There is a tendency for the \% yield to decrease as the ethanol \% increases. There is a tendency for the $\%$ yield to decrease as the ethanol $\%$ increases. For both methodologies, the lowest yield was obtained in run 14 (HAE: $62.5 \mathrm{~min}$; $60{ }^{\circ} \mathrm{C} ; 100 \%$

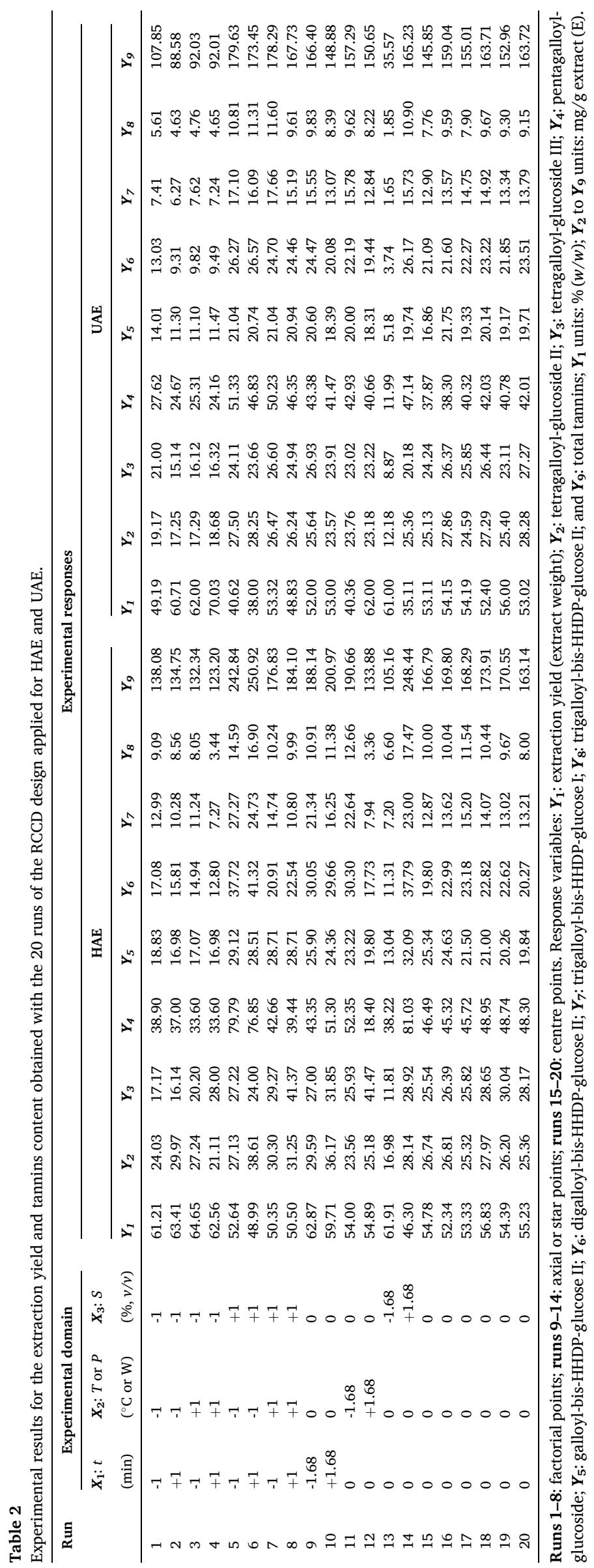


ethanol $v / v$ and UAE: $23.5 \mathrm{~min} ; 253 \mathrm{~W}$; 100\% ethanol $v / v$ ), which combined medium-time and -temperature/-watts potency $(\alpha=0)$ with a high-ethanol percentage $(\alpha=+1.68)$. The highest yield was obtained in run 3 for HAE ( $28 \mathrm{~min} ; 81^{\circ} \mathrm{C} ; 20 \%$ ethanol $v / v$ ) and run 4 for UAE (36 min; $400 \mathrm{~W} ; 20 \%$ ethanol $v / v)$. Run 3 combined medium-high -temperature $(\alpha=+1)$ with medium-low-time and -ethanol percentage ( $\alpha=$ $-1)$ and run 4 merges medium-low ethanol percentage $(\alpha=-1)$ with medium-high -time and -watts potency $(\alpha=+1)$.

As presented in Table 2, the seven optimised hydrolysable tannins were $Y_{2}$ and $Y_{3}$ - two tetragalloyl-glucoside isomers (II and III), $Y_{4}$, pentagalloyl-glucoside, $Y_{5^{-}}$galloyl-bis-HHDP-glucose II, $Y_{6}$ - digalloylbis-HHDP-glucose II, $Y_{7}$ and $Y_{8}$ - two trigalloyl-bis-HHDP-glucose isomers (I and II), and $Y_{9}$ - tannins (total). From the analysis of the HAE experimental results for the 7 tannins (Table 2), it is possible to observe that, in 4 responses $\left(Y_{2}, Y_{6}, Y_{7}\right.$, and $\left.Y_{9}\right)$, the lowest yield was obtained in run 13 (HAE: $62.5 \mathrm{~min} ; 60{ }^{\circ} \mathrm{C}$; $0 \%$ ethanol $v / v$ ), which combined medium-time and -temperature $(\alpha=0)$ with a $0 \%$ of ethanol $(\alpha=-1.68)$. Whereas the highest yield was obtained in run 6 (HAE: $97 \mathrm{~min} ; 39{ }^{\circ} \mathrm{C}$; $80 \%$ ethanol $v / v$ ), combining medium-high-time and -ethanol percentage $(\alpha=+1)$ with medium-low-temperature $(\alpha=-1)$. For responses $Y_{4}$, $Y_{5}$, and $Y_{8}$, the highest response value was obtained in run 14 (HAE: $62.5 \mathrm{~min} ; 60{ }^{\circ} \mathrm{C} ; 100 \%$ ethanol $\left.v / v\right)$, in a mixture of medium-time and -temperate $(\alpha=0)$ with the highest ethanol percentage $(\alpha=+1.68)$. Responses $Y_{4}, Y_{5}$, and $Y_{8}$ lowest experimental values were obtained in run 12 for $Y_{4}$ and $Y_{8}$ (HAE: $62.5 \mathrm{~min} ; 95{ }^{\circ} \mathrm{C} ; 0 \%$ ethanol $v / v$ ) and run 13 for $Y_{5}$ (HAE: $62.5 \mathrm{~min} ; 60^{\circ} \mathrm{C}$; $0 \%$ ethanol $v / v$ ), both using $0 \%$ of ethanol
( $\alpha=-1.68)$, and high $(\alpha=+1)$ to medium-high-temperature ( $\alpha=+$ $1.68)$, respectively. A general overview of the HAE experimental values revealed higher ethanol percentages as the critical factor in increasing the 7 hydrolysable tannins final responses (response $Y_{2}$ to $Y_{8}$ ).

Regarding UAE (Table 2), the lowest experimental values for all tannins were obtained in run 13 (UAE: $23.5 \mathrm{~min} ; 253 \mathrm{~W}$; $0 \%$ ethanol $v$ / $v)$, combining medium-time and -watts $(\alpha=0)$ with no ethanol $(\alpha=$ -1.68). Equally to HAE, in UAE, low ethanol ( $0 \%)$ was linked to lower experimental response values for tannins $\left(Y_{2}\right.$ to $Y_{9}$ ). For responses $Y_{2}$, $Y_{3}$, and $Y_{5}$, the highest experimental values were obtained within the 6 centre points (UAE: $23.5 \mathrm{~min} ; 253 \mathrm{~W} ; 50 \%$ ethanol $v / v$ ), which combined medium $t, P$ and $S(\alpha=0)$. Whereas for responses $Y_{4}$ and $Y_{9}$, it was in run 5 (UAE: $11 \mathrm{~min} ; 106 \mathrm{~W} ; 80 \%$ ethanol $v / v$ ), with $\alpha=-1 ;-1 ;+1$, respectively. Run 6 (UAE: $36 \mathrm{~min} ; 106 \mathrm{~W} ; 80 \%$ ethanol $v / v$ ) was the best result for $Y_{6}$ response, with $\alpha=+1 ;-1 ;+1$, respectively. Finally, for responses $Y_{7}$ and $Y_{8}$, the best result was obtained in run 7 (UAE: $11 \mathrm{~min}$; $400 \mathrm{~W} ; 80 \%$ ethanol $v / v$ ), with $\alpha=-1 ;+1 ;+1$. Similarly to HAE, the UAE experimental values pointed to the ethanol percentage as the critical factor to obtain higher yields in responses $Y_{2}$ to $Y_{8}$.

\subsection{Models fitting and statistical verification}

The conventional one-factor-at-a-time strategies do not account for interactions, while RSM is a statistical tool suitable for modelling and optimising processes involving one or more response variables and determining optimal processing conditions [21,32]. To further analyse

Table 3

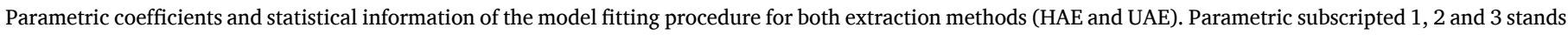
for the variables $t, T / P$ and $S$, respectively.

\begin{tabular}{|c|c|c|c|c|c|c|c|c|c|c|}
\hline \multicolumn{2}{|c|}{ HAE } & \multirow{2}{*}{$\begin{array}{l}\boldsymbol{Y}_{1} \\
54.4 \pm 0.4\end{array}$} & \multirow{2}{*}{$\frac{Y_{2}}{26.1 \pm 0.6}$} & \multirow{2}{*}{$\frac{Y_{3}}{27.7 \pm 0.6}$} & \multirow{2}{*}{$\frac{Y_{4}}{47.3 \pm 0.7}$} & \multirow{2}{*}{$\frac{Y_{5}}{22.1 \pm 0.4}$} & \multirow{2}{*}{$\begin{array}{l}Y_{6} \\
22.2 \pm 0.6\end{array}$} & \multirow{2}{*}{$\begin{array}{l}\boldsymbol{Y}_{7} \\
14.0 \pm 0.3\end{array}$} & \multirow{2}{*}{$\frac{Y_{\boldsymbol{8}}}{10.3 \pm 0.4}$} & \multirow{2}{*}{$\begin{array}{l}\boldsymbol{Y}_{\mathbf{9}} \\
170 \pm 2\end{array}$} \\
\hline Intercept & $b_{o}$ & & & & & & & & & \\
\hline & $b_{1}$ & $-0.6 \pm 0.4^{*}$ & $1.7 \pm 0.4$ & $1.8 \pm 0.5$ & ns & $-0.4 \pm 0.4^{*}$ & $0.1 \pm 0.6^{*}$ & $-1.6 \pm 0.3$ & $-0.2 \pm 0.3^{*}$ & $2 \pm 1 *$ \\
\hline \multirow[t]{3}{*}{ Linear effect } & $b_{2}$ & ns & $-0.5 \pm 0.4^{*}$ & $4.4 \pm 0.5$ & $-10.3 \pm 0.6$ & ns & $-4.5 \pm 0.6$ & $-4.1 \pm 0.3$ & $-2.4 \pm 0.3$ & $-18 \pm 1$ \\
\hline & $b_{3}$ & $-5.5 \pm 0.4$ & $3.2 \pm 0.4$ & $5.1 \pm 0.5$ & $12.3 \pm 0.6$ & $5.7 \pm 0.4$ & $7.8 \pm 0.6$ & $4.6 \pm 0.3$ & $2.3 \pm 0.3$ & $42 \pm 1$ \\
\hline & $b_{11}$ & $2.4 \pm 0.4$ & $2.8 \pm 0.4$ & ns & ns & $1.1 \pm 0.4$ & $2.0 \pm 0.6$ & $1.4 \pm 0.3$ & ns & $8 \pm 1$ \\
\hline \multirow[t]{3}{*}{ Quadratic effect } & $b_{22}$ & ns & ns & $1.7 \pm 05$ & $-4.1 \pm 0.5$ & ns & ns & ns & $-0.8 \pm 0.3$ & $-4 \pm 1$ \\
\hline & $b_{33}$ & ns & $\mathrm{ns}$ & $-3.0 \pm 0.5$ & $4.4 \pm 0.5$ & ns & ns & ns & $0.6 \pm 0.3$ & ns \\
\hline & $b_{12}$ & ns & $-2.8 \pm 0.6$ & $3.0 \pm 0.7$ & ns & ns & ns & ns & $-0.8 \pm 0.4$ & ns \\
\hline \multirow[t]{5}{*}{ Interaction effect } & $b_{13}$ & ns & $1.6 \pm 0.6$ & ns & ns & ns & ns & ns & $0.9 \pm 0.4$ & ns \\
\hline & $b_{23}$ & ns & $\mathrm{ns}$ & ns & $-8.2 \pm 0.7$ & ns & $-3.8 \pm 0.8$ & $-2.7 \pm 0.4$ & ns & $-14 \pm 2$ \\
\hline & Model F-value & 82.48 & 21.86 & 44.24 & 222.00 & 67.67 & 52.95 & 116.74 & 27.55 & 192.24 \\
\hline & Model $p$-value & $<0.0001$ & $<0.0001$ & $<0.0001$ & $<0.0001$ & $<0.0001$ & $<0.0001$ & $<0.0001$ & $<0.0001$ & $<0.0001$ \\
\hline & Lack-of-Fit & 0.6565 & 0.0847 & 0.4672 & 0.2349 & 0.9957 & 0.1343 & 0.2933 & 0.7060 & 0.1944 \\
\hline \multirow[t]{4}{*}{ Statistics } & $\mathrm{R}^{2}$ & 0.9393 & 0.9273 & 0.9533 & 0.9875 & 0.9269 & 0.9498 & 0.9766 & 0.9525 & 0.9912 \\
\hline & $\mathrm{R}_{\text {adj }}^{2}$ & 0.9279 & 0.8849 & 0.9318 & 0.9831 & 0.9132 & 0.9318 & 0.9682 & 0.9179 & 0.9860 \\
\hline & Ad. Precision & 28.99 & 19.24 & 27.20 & 55.58 & 28.42 & 25.97 & 38.57 & 20.66 & 50.53 \\
\hline & C.V. (\%) & 2.56 & 5.88 & 6.97 & 4.30 & 6.57 & 9.35 & 6.97 & 10.16 & 2.77 \\
\hline \multicolumn{2}{|c|}{ UAE } & $Y_{1}$ & $Y_{2}$ & $Y_{3}$ & $Y_{4}$ & $Y_{5}$ & $Y_{6}$ & $Y_{7}$ & $Y_{8}$ & $Y_{9}$ \\
\hline \multirow[t]{2}{*}{ Intercept } & $b_{o}$ & $53.5 \pm 0.5$ & $26.0 \pm 0.4$ & $25.5 \pm 0.5$ & $41.0 \pm 0.5$ & $19.3 \pm 0.3$ & $22.1 \pm 0.4$ & $14.0 \pm 0.2$ & $8.9 \pm 0.2$ & $156 \pm 2$ \\
\hline & $b_{1}$ & $1.0 \pm 0.5$ & ns & $-0.9 \pm 0.4$ & $-1.2 \pm 0.4$ & ns & $-0.8 \pm 0.3$ & $-0.7 \pm 0.2$ & $-0.4 \pm 0.2$ & $-5 \pm 1$ \\
\hline \multirow[t]{3}{*}{ Linear effect } & $b_{2}$ & $6.0 \pm 0.5$ & $-0.3 \pm 0.3^{*}$ & $0.1 \pm 0.3^{*}$ & ns & ns & $-0.8 \pm 0.3$ & $\mathrm{~ns}$ & ns & ns \\
\hline & $b_{3}$ & $-7.7 \pm 0.5$ & $4.3 \pm 0.3$ & $3.6 \pm 0.4$ & $11.1 \pm 0.4$ & $4.4 \pm 0.3$ & $7.2 \pm 0.3$ & $4.5 \pm 0.2$ & $2.9 \pm 0.2$ & $39 \pm 1$ \\
\hline & $b_{11}$ & ns & ns & ns & ns & ns & ns & ns & ns & ns \\
\hline \multirow[t]{3}{*}{ Quadratic effect } & $b_{22}$ & ns & $-0.9 \pm 0.3$ & $-0.8 \pm 0.4$ & ns & ns & $-0.7 \pm 0.3$ & ns & ns & ns \\
\hline & $b_{33}$ & $-1.5 \pm 0.4$ & $-2.5 \pm 0.3$ & $-3.9 \pm 0.4$ & $-4.0 \pm 0.4$ & $-2.6 \pm 0.3$ & $-2.8 \pm 0.3$ & $-2.0 \pm 0.2$ & $-0.9 \pm 0.2$ & $-20 \pm 1$ \\
\hline & $b_{12}$ & ns & $\mathrm{ns}$ & ns & ns & ns & $\mathrm{ns}$ & ns & ns & ns \\
\hline \multirow[t]{5}{*}{ Interaction effect } & $b_{13}$ & $-3.3 \pm 0.6$ & ns & ns & ns & ns & ns & ns & ns & ns \\
\hline & $b_{23}$ & ns & $\mathrm{ns}$ & ns & ns & ns & ns & ns & ns & $\mathrm{ns}$ \\
\hline & Model F-value & 97.35 & 52.78 & 37.36 & 251.84 & 130.72 & 118.46 & 165.23 & 80.26 & 328.30 \\
\hline & Model $p$-value & $<0.0001$ & $<0.0001$ & $<0.0001$ & $<0.0001$ & $<0.0001$ & $<0.0001$ & $<0.0001$ & $<0.0001$ & $<0.0001$ \\
\hline & Lack-of-Fit & 0.1941 & 0.8314 & 0.7392 & 0.7002 & 0.9319 & 0.2429 & 0.4954 & 0.9365 & 0.9097 \\
\hline \multirow[t]{4}{*}{ Statistics } & $\mathrm{R}^{2}$ & 0.9720 & 0.9337 & 0.9452 & 0.9793 & 0.9389 & 0.9769 & 0.9687 & 0.9554 & 0.9840 \\
\hline & $\mathrm{R}_{\text {adj }}^{2}$ & 0.9621 & 0.9160 & 0.9199 & 0.9754 & 0.9318 & 0.9687 & 0.9629 & 0.9435 & 0.9810 \\
\hline & Ad. Precision & 36.21 & 24.14 & 22.99 & 53.41 & 36.23 & 38.78 & 44.14 & 31.88 & 62.36 \\
\hline & C.V. (\%) & 3.27 & 5.44 & 6.11 & 4.20 & 6.71 & 6.06 & 6.52 & 7.61 & 3.70 \\
\hline
\end{tabular}

Response variables: $\boldsymbol{Y}_{\mathbf{1}}$ : extraction yield (extract weight); $\boldsymbol{Y}_{\mathbf{2}}$ : tetragalloyl-glucoside II; $\boldsymbol{Y}_{\mathbf{3}}$ : tetragalloyl-glucoside III; $\boldsymbol{Y}_{\mathbf{4}}$ : pentagalloyl-glucoside; $\boldsymbol{Y}_{5}$ : galloyl-bis-HHDPglucose II; $\boldsymbol{Y}_{\mathbf{6}}$ : digalloyl-bis-HHDP-glucose II; $\boldsymbol{Y}_{\mathbf{7}}$ : trigalloyl-bis-HHDP-glucose I; $\boldsymbol{Y}_{\mathbf{8}}$ : trigalloyl-bis-HHDP-glucose II; and $\boldsymbol{Y}_{\mathbf{9}}$ : total tannins. R ${ }^{2}$ : coefficient of determination; $\mathrm{R}^{2}$ ajd: adjusted coefficient of determination; Ad. Precision: Adequate Precision; C.V.: coefficient of variation; ns: not significant. *Statistically non-significant ( $p$ value $>0.05$ ) terms added to maintain hierarchy. 
the experimental values (section 3.2.), the polynomial model (Eq. 1) was applied to assess the impact of the independent variables on a given response. By fitting the second-order polynomial model to the obtained experimental responses, the parametric values were estimated and presented in Table 3.

The coefficients exhibiting confidence interval values $(\alpha=0.05)$ higher than the parameter value were considered non-significant ( $n s$ ) and were not used for model development; the significant values were assessed at a 95\% confidence level. The results of ANOVA and regression analyses are also presented in Table 3, whereas the developed polynomial models are shown in Table 4 (Eq. 2 to Eq. 19). All models exhibited a non-significant (ns) lack-of-fit ( $p$-values $>0.05$ ) and adequate precision $>19.2$, which shows that the model equations adequately describe the effects of the independent variables on the final responses [33]. As shown in Table 3 , the coefficients $R^{2}$ and $R^{2}$ adj were $\geq 0.92$ and 0.88 , respectively, indicating that each response variability can be explained by the independent variables involved in the extraction processes. Although the model coefficients are empirical and do not reflect physical or chemical significance, they are valuable tools to predict the untested experimental extraction conditions [34]. All models proved to be statistically adequate and were used to navigate the design space in the optimisation steps.

\subsection{Analysis of the theoretical response surface models}

The parametric coefficients presented of each term in the mathematical models (Table 4) provide specific information on the impact of the linear, quadratic, and interaction effects of the independent variables $(t, T / P$, and $S$ ) on the extraction of tannins from $C$. hypocistis. The values express the expected change in response per unit change in factor value when all remaining factors are held constant. The higher the parametric value, the more significant is the variable term, regardless of its sign. Additionally, for interaction effects, a positive sign indicates a synergism, while a negative sign indicates an antagonism (since the effect of one independent variable is affected by another variable) $[21,35]$. The results are also presented as 3D response surface graphs to visually illustrate the independent variables effect on extraction yield (Fig. 1) and total tannins (Fig. 2) for both HAE and UAE methods. The net surfaces were built with the model equations presented in Table 4.

Table 4

The quadratic second-order polynomial model Eq. (1) and the developed polynomial model Eqs. (2)-(19) expressed in coded values.

\begin{tabular}{llll}
\hline $\begin{array}{l}Y=b_{0}+b_{1} X_{1}+b_{2} X_{2}+b_{3} X_{3}+b_{11} X_{1}^{2}+b_{22} X_{2}^{2}+b_{33} X_{3}^{2}+b_{12} X_{1} X_{2}+ \\
b_{13} X_{1} X_{3}+b_{23} X_{2} X_{3}\end{array}$ & $\begin{array}{l}\text { Eq. } \\
\text { For HAE }\end{array}$ & For UAE \\
\hline$Y_{1}=54.4-0.6 t-5.5 S+2.4 t^{2}$ & Eq. & $Y_{1}=53.5+1.0 t+6 P-$ & Eq. \\
& $(2)$ & $7.7 S-1.5 S^{2}-3.3 t P$ & $(11)$ \\
$Y_{2}=26.1+1.7 t-0.5 T+3.2 S+$ & Eq. & $Y_{2}=26-0.3 P+4.3 S-$ & Eq. \\
$2.8 t^{2}-2.8 t T+1.6 t S$ & $(3)$ & $0.9 P^{2}-2.5 S^{2}$ & $(12)$ \\
$Y_{3}=27.7+1.8 t+4.4 T+5.1 S+$ & Eq. & $Y_{3}=25.5+0.1 P-0.9 t+$ & Eq. \\
$1.7 T^{2}-3 S^{2}+3 t T$ & $(4)$ & $3.6 S-0.8 P^{2}-3.9 S^{2}$ & $(13)$ \\
$Y_{4}=47.3-10.3 T+12.3 S-4.1$ & Eq. & $Y_{4}=41-1.2 t+11.1 S-$ & Eq. \\
$T^{2}+4.4 S^{2}-8.2 T S$ & $(5)$ & $4.0 S^{2}$ & $(14)$ \\
$Y_{5}=22.1-0.4 t+5.7 S+1.1 t^{2}$ & Eq. & $Y_{5}=19.3+4.4 S-2.6 S^{2}$ & Eq. \\
& $(6)$ & & $(15)$ \\
$Y_{6}=22.2+0.1 t-4.5 T+7.8 S+$ & Eq. & $Y_{6}=22.1-0.8 t-0.8 P+$ & Eq. \\
$2 t^{2}-3.8 T S$ & $(7)$ & $7.2 S-0.7 P^{2}-2.8 S^{2}$ & $(16)$ \\
$Y_{7}=14.0-16.6 t-4.1 T+4.6 S+$ & Eq. & $Y_{7}=14-0.7 t+4.5 S-$ & Eq. \\
$1.4 t^{2}-2.7 T S$ & $(8)$ & $2 S^{2}$ & $(17)$ \\
$Y_{8}=10.3-0.2 t-2.4 T+2.3 S-$ & Eq. & $Y_{8}=8.9-0.4 t+2.9 S-$ & Eq. \\
$0.8 T^{2}+0.6 S^{2}-0.8 t T+0.9 t S$ & $(9)$ & $0.9 S^{2}$ & $(18)$ \\
$Y_{9}=170+2 t-18 T+42 S+8 t^{2}-$ & Eq. & $Y_{9}=156-5 t+39 S-$ & Eq. \\
$4 T^{2}-14 T S$ & $(10)$ & $20 S^{2}$ & $(19)$ \\
\hline
\end{tabular}

Response variables: $\boldsymbol{Y}_{\mathbf{1}}$ : extraction yield (extract weight); $\boldsymbol{Y}_{\mathbf{2}}$ : tetragalloylglucoside II; $\boldsymbol{Y}_{3}$ : tetragalloyl-glucoside III; $\boldsymbol{Y}_{4}$ : pentagalloyl-glucoside; $\boldsymbol{Y}_{5}$ : galloyl-bis-HHDP-glucose II; $\mathbf{Y}_{\mathbf{6}}$ : digalloyl-bis-HHDP-glucose II; $\mathbf{Y}_{\mathbf{7}}$ : trigalloylbis-HHDP-glucose I; $\boldsymbol{Y}_{\mathbf{8}}$ : trigalloyl-bis-HHDP-glucose II; and $\boldsymbol{Y}_{\mathbf{g}}$ : total tannins.
For each 3D graph, the excluded independent variable was positioned at its optimal value (Table 5).

The intercept is the expected mean value of $Y$ (response) when all independent variables are equal to zero $(X=0)$. As shown in Table 3 , although the two designs (HAE and UAE) present similar intercept values for all nine responses, for $Y_{3}, Y_{4}, Y_{5}, Y_{8}$, and $Y_{9}$, the HAE values were slightly superior. Regarding the HAE- $Y_{1}$ response, the variables $S$ and $t$ significantly affected the extraction yield. The negative linear effect of solvent $(-5.5 S)$ is perfectly illustrated by the surface curvature of the graphs, where this variable is represented (Fig. $1 \mathbf{b}$ and $\mathbf{c}$ ). The positive quadratic effect of time $\left(2.4 t^{2}\right)$ is visible in Fig. $1 \mathbf{a}$ and $\mathbf{b}$. Apart from the variables $S$ and $t, P$ also influenced the UAE-Y $Y_{1}$ response. The variables $t$ and $P$ had a positive linear effect ( $1 t$ and $6 P$, respectively), which is visible in Fig. 1d; whereas $S$ and its quadratic effect had a negative impact on $Y_{1}\left(-7.7 S\right.$ and $-1.5 S^{2}$, respectively), evidenced by the curvature in graphs (d) and (e) of Fig. 1. For both methods, it was possible to observe the importance of the solvent $(S)$ variable, an increase in ethanol concentration presented the most significant impact (negative) on the two $Y_{1}$ responses (Fig. 1).

Concerning total tannins, the response surfaces obtained for HAE were more complex than those of UAE (Figs. 1 and 2), as predicted by the theoretical models (Eqs. 10 and 19 in Table 4). Considering tannins final responses for HAE, the linear impact of ethanol $(S)$ was positive for all responses, whereas the other variables presented both positive and negative effects on the final responses. The linear effect of $t$ was positive for responses $Y_{2}(1.7 t)$ and $Y_{3}(1.8 t)$, negative for $Y_{5}(-0.4 t)$ and $Y_{7}(-1.6$ $t$ ), and non-significant for $Y_{4}, Y_{6}, Y_{8}$, and $Y_{9}$. The linear effect of $T$ was positive for $Y_{3}(4.4 T)$, negative for $Y_{4}(-10.3 T), Y_{7}(-4.5 T), Y_{8}(-4.1 T)$, and $Y_{9}(-2.4 T)$, and non-significant for the remaining two responses $\left(Y_{2}\right.$ and $Y_{6}$ ). Concerning the quadratic effect of the independent variables $t^{2}$, $T^{2}$, and $S^{2}: t^{2}$ positively affected $Y_{2}\left(2.8 t^{2}\right), Y_{5}\left(1.1 t^{2}\right), Y_{6}\left(2.0 t^{2}\right), Y_{7}$ $\left(1.4 t^{2}\right)$, and $Y_{9}\left(8.0 t^{2}\right)$ final responses; $T^{2}$ affected positively the response $Y_{3}\left(1.7 T^{2}\right)$ and negatively $Y_{4}\left(-4.1 T^{2}\right), Y_{8}\left(-0.8 T^{2}\right)$, and $Y_{9}$ $\left(-4.0 T^{2}\right)$; while $S^{2}$ positively impacted $Y_{4}\left(4.4 S^{2}\right)$ and $Y_{8}\left(0.6 S^{2}\right)$ and had a negative effect on $Y_{3}\left(-3.0 S^{2}\right)$. For all the other responses, the quadratic effects of the independent variables were non-significant. Finally, for the interaction effects of the independent variables during HAE, it was possible to observe that the interaction effect of $T$ and $S$ was either nonsignificant or had a negative effect on the tannin final responses $\left(Y_{4}\right.$ : -8.2TS, $Y_{6}:-3.8 T S, Y_{7}:-2.7 T S$, and $\left.Y_{9}:-14 T S\right)$. The interaction effect of $t$ and $T$ negatively affected $Y_{2}:-2.8 t T$ and $Y_{8}:-0.8 t T$ responses; contrarily, it had a positive effect on $Y_{3}(3.0 t T)$ response. The interaction effect between $t$ and $S$ also had a positive impact on $Y_{2}: 1.6 t S$ and $Y_{8}: 0.9 t S$. For all the other responses, the interaction effect was non-significant. Similarly to the values obtained for the 20 experimental runs (Table 3), it was possible to infer the importance of the solvent $(S)$ variable on tannins final responses from the mathematical models presented in Table 4; $S$ had the most significant impact (positive) on responses $Y_{2}$ to $Y_{9}$. Regarding total tannins $\left(Y_{9}\right)$, Fig. 2 pictures the positive impact of both low $T$, perfectly noticeable in graphs (a) and (c), and high $S$, visible in graphs (b) and (c) and graphs (e) and (f) for HAE and UAE, respectively.

During the UAE method, the linear effect of the variable $S$ was responsible for the only positive effect in all tannin responses ( $Y_{2}$ to $Y_{9}$ ). UAE of total tannins $\left(Y_{g}\right)$ was mainly affected by the independent variable $S$. The highest quantity of total tannins was obtained when C. hypocistis powder was sonicated with high ethanol percentages; this effect is noticeable on the surface graphs where this variable is represented (Fig. $2 \mathbf{e}$ and $\mathbf{f}$ ). The ultrasonic power $(P)$ and time $(t)$ variables had a non-significant or slightly negative effect (respectively) on this response (Fig. 2d). Despite the positive linear effect of $S$, its quadratic effect $\left(S^{2}\right)$ was negative for all responses. When present, the linear effect of $P\left(Y_{6}:-0.8 P\right)$ and the quadratic effect of $P^{2}\left(Y_{2}:-0.9 P^{2} ; Y_{3}:-0.8 P^{2}\right.$; and $\left.Y_{6}:-0.7 P^{2}\right)$ had a minor negative or non-significant impact on all the final responses. The quadratic effect of $S^{2}$ had a negative effect on all the responses, from $-20.0 S^{2}$ to $-0.9 S^{2}$. Differently, no interaction effects were 


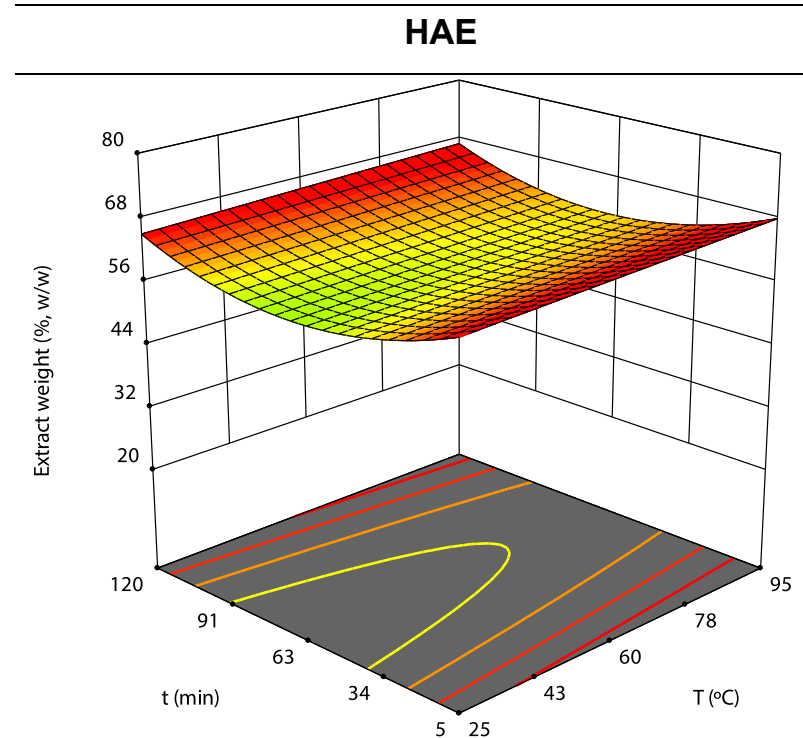

(a)

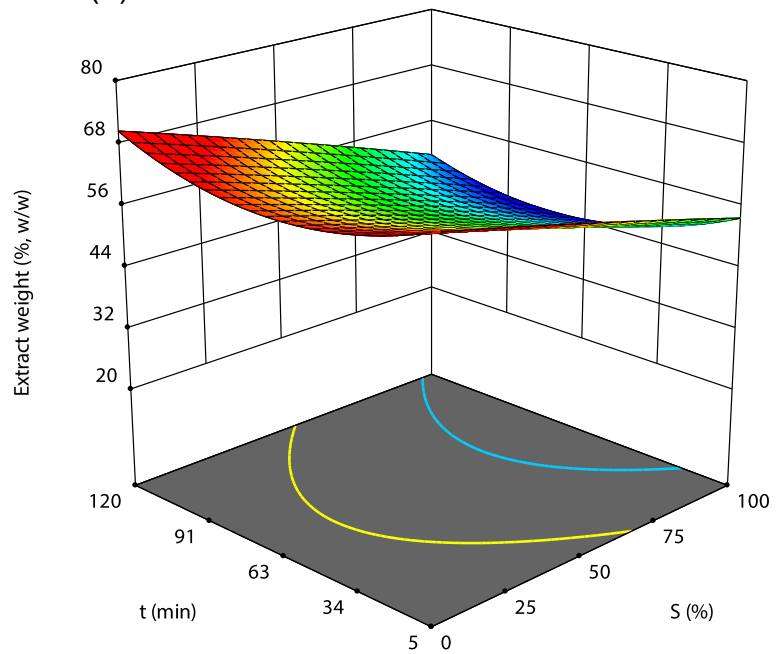

(b)

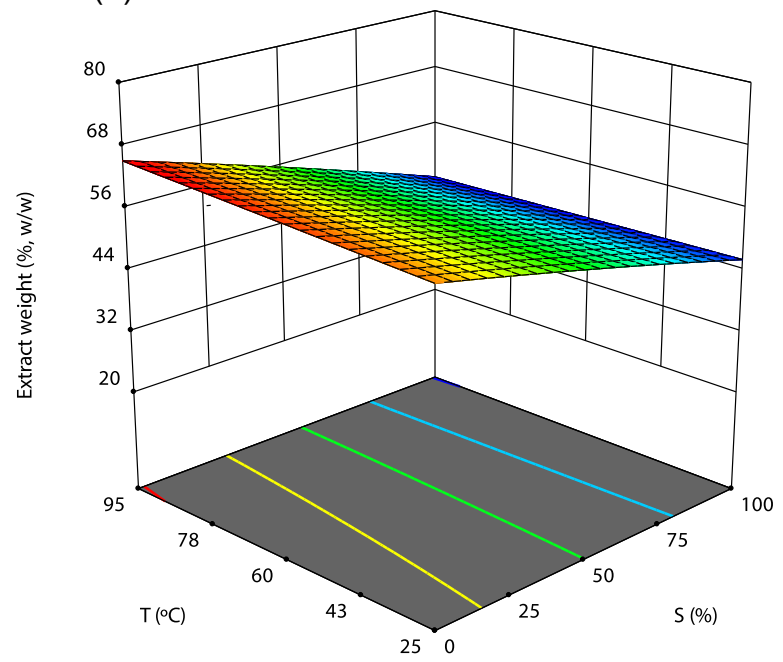

(c)

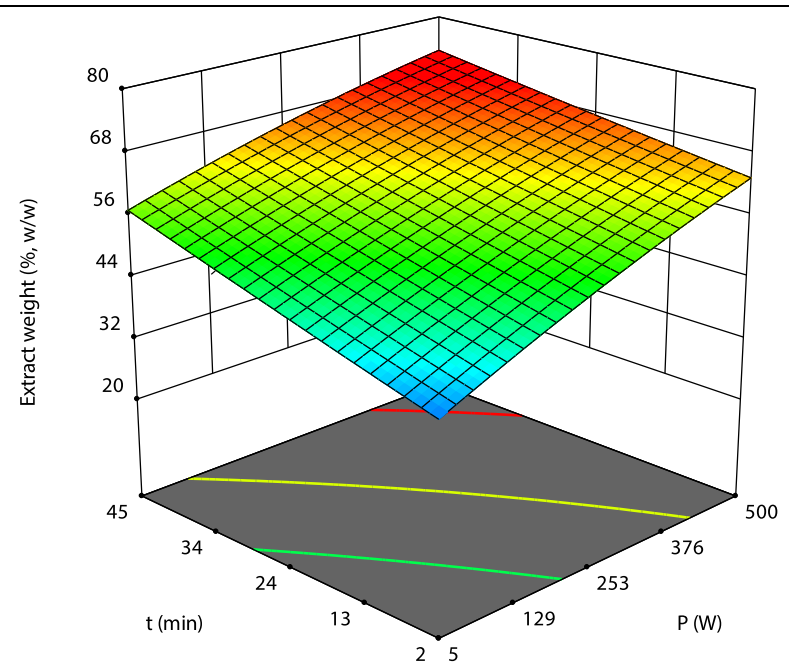

(d)

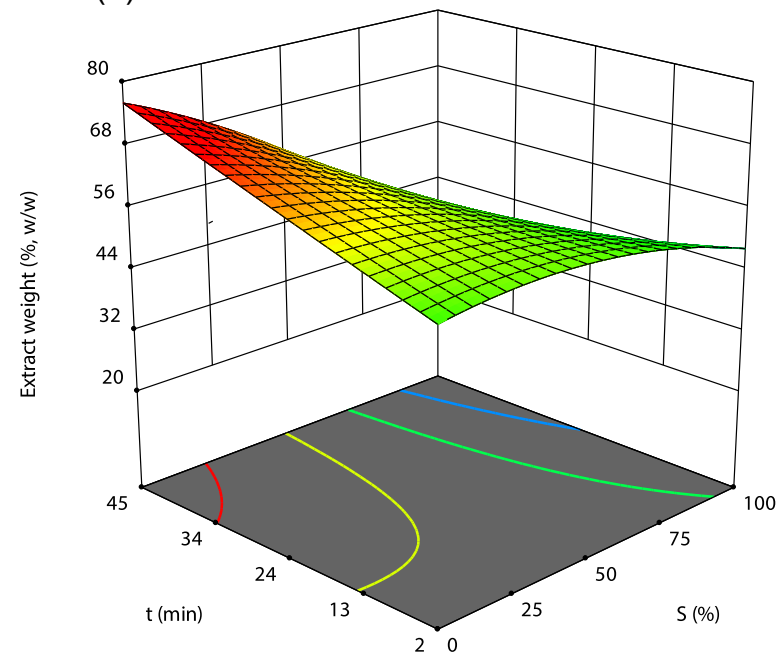

(e)

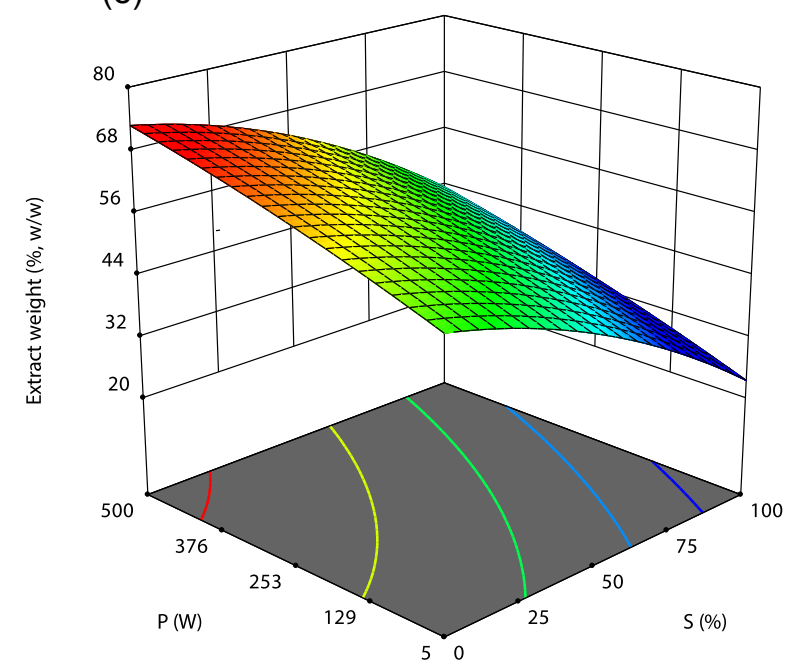

(f)

Fig. 1. Response surface graphs illustrating the binary effects of the independent variables on the extraction yield ( $Y_{1}$ : extract weight) obtained with HAE and UAE. In each graph, the excluded variable was fixed at its optimum response value (Table 5). 


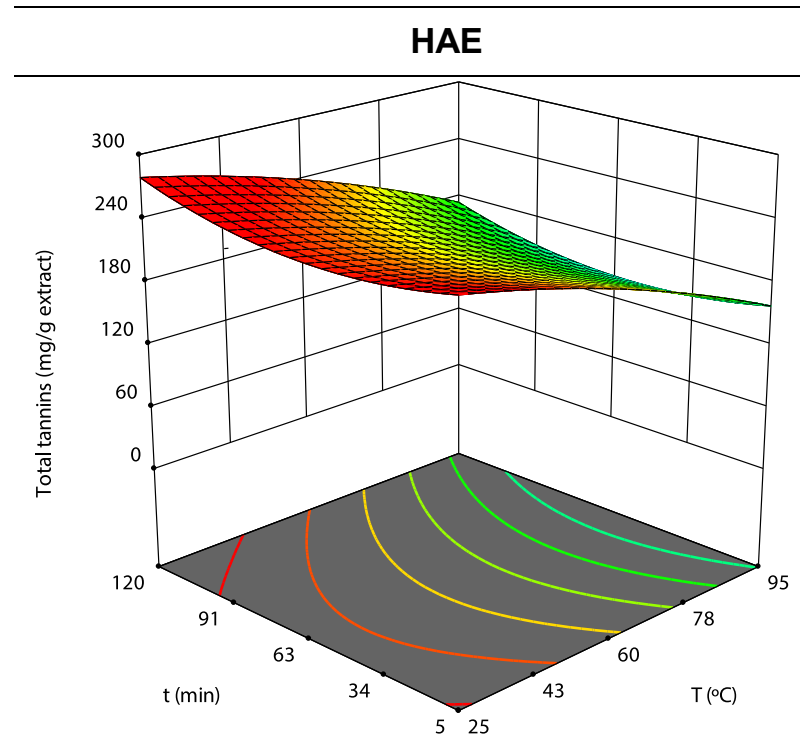

(a)

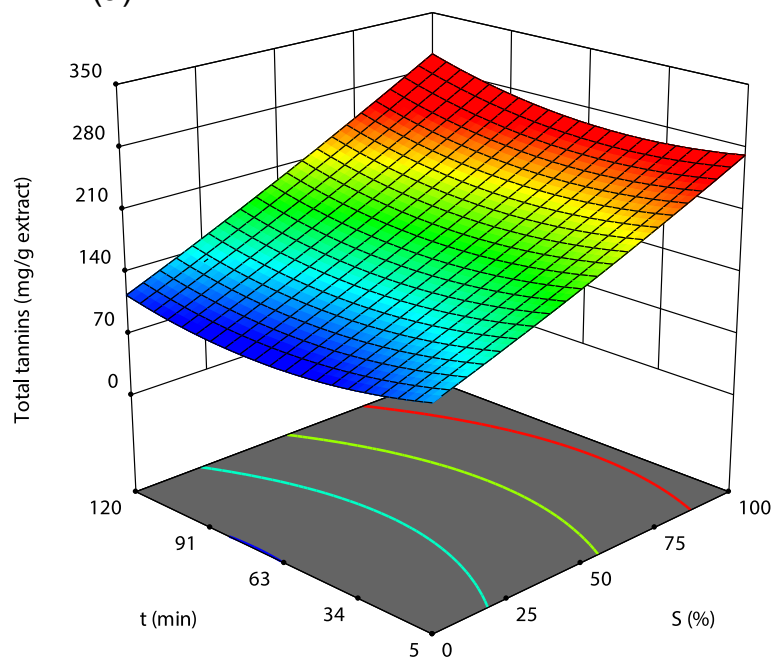

(b)

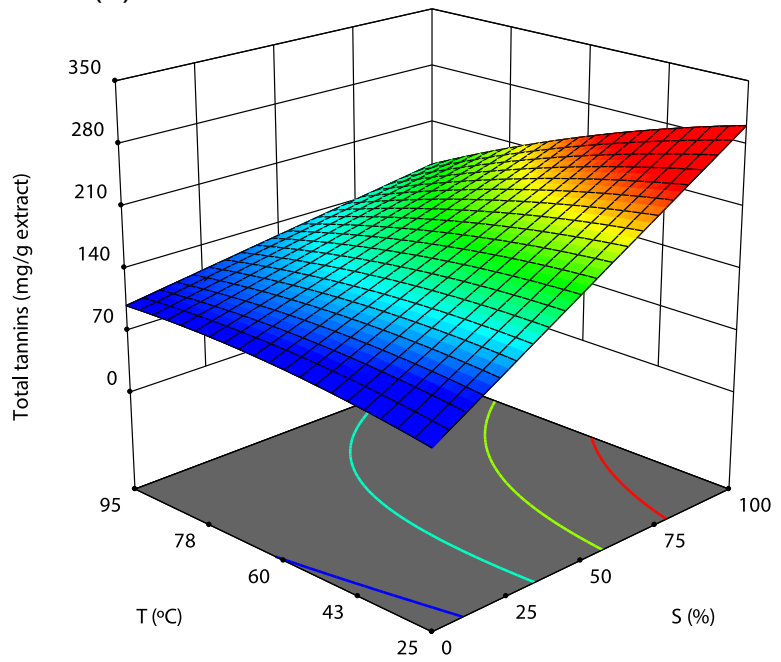

(c)

\section{UAE}

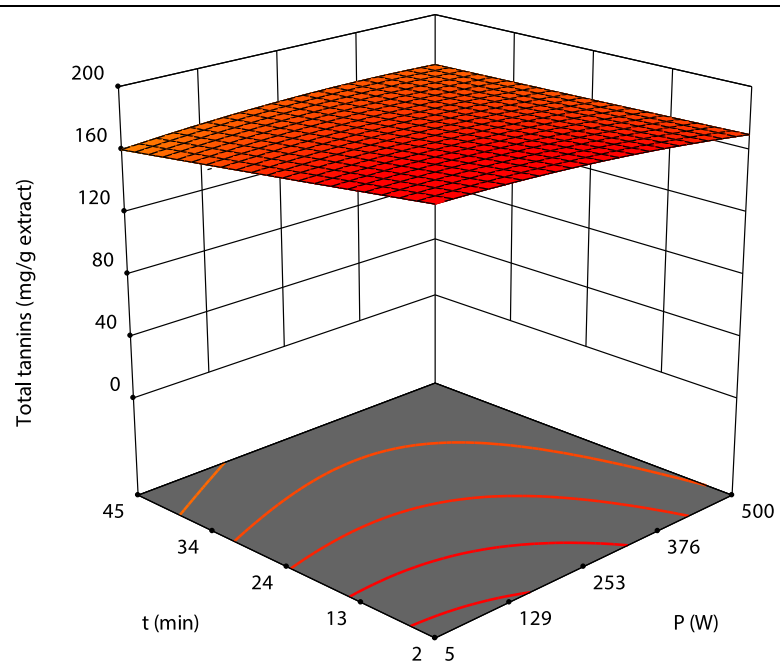

(d)

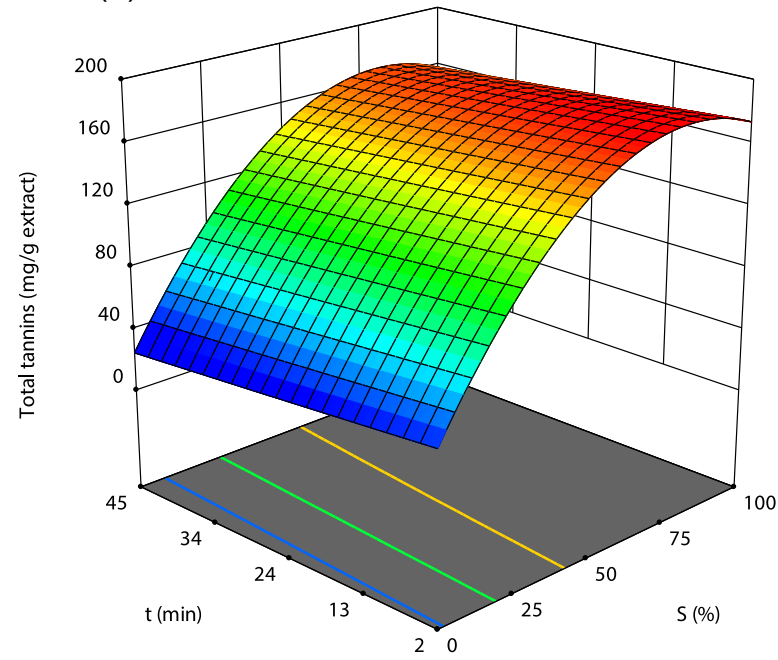

(e)

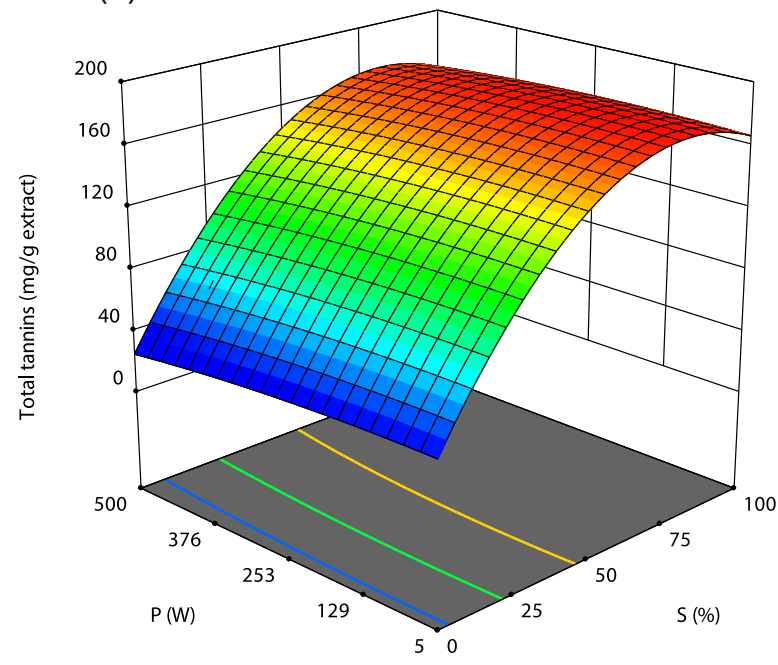

(f)

Fig. 2. Response surface graphs illustrating the binary effects of the independent variables on the total tannin content $\left(Y_{9}\right)$ obtained with HAE and UAE. In each graph, the excluded variable was fixed at its optimum response value (Table 5). 
Table 5

Optimal HAE and UAE conditions expressed as natural values that lead the individual and grouped dependent variables to optimal response values.

\begin{tabular}{|c|c|c|c|c|}
\hline & \multicolumn{3}{|c|}{ Optimal HAE conditions } & \multirow[t]{2}{*}{ Optimum response } \\
\hline & $t(\min )$ & $T\left({ }^{\circ} \mathrm{C}\right)$ & $S($ ethanol $\%, v / v$ ) & \\
\hline \multicolumn{5}{|c|}{ For each response variable } \\
\hline$Y_{1}$ & 27.3 & 45.5 & 0.0 & $67 \pm 1 \%(w / w)$ \\
\hline$Y_{2}$ & 104.0 & 51.3 & 65.9 & $36.4 \pm 0.9 \mathrm{mg} / \mathrm{g} \mathrm{E}$ \\
\hline$Y_{3}$ & 79.0 & 83.0 & 69.9 & $39.5 \pm 0.9 \mathrm{mg} / \mathrm{g} \mathrm{E}$ \\
\hline$Y_{4}$ & 62.5 & 48.7 & 83.7 & $76 \pm 1 \mathrm{mg} / \mathrm{g} \mathrm{E}$ \\
\hline$Y_{5}$ & 57.8 & 60.0 & 95.9 & $30.9 \pm 0.8 \mathrm{mg} / \mathrm{g} \mathrm{E}$ \\
\hline$Y_{6}$ & 89.9 & 50.7 & 96.1 & $40 \pm 1 \mathrm{mg} / \mathrm{g} \mathrm{E}$ \\
\hline$Y_{7}$ & 29.3 & 44.1 & 82.5 & $27.3 \pm 0.6 \mathrm{mg} / \mathrm{g} \mathrm{E}$ \\
\hline$Y_{8}$ & 70.8 & 48.0 & 85.4 & $16.6 \pm 0.6 \mathrm{mg} / \mathrm{g} \mathrm{E}$ \\
\hline$Y_{9}$ & 65.7 & 52.1 & 98.8 & $245 \pm 3 \mathrm{mg} / \mathrm{g} \mathrm{E}$ \\
\hline \multicolumn{5}{|c|}{ Considering all response variables } \\
\hline$Y_{1}$ & 95.1 & 46.4 & 74.3 & $53 \pm 1 \%(w / w)$ \\
\hline \multirow[t]{3}{*}{$Y_{9}$} & & & & $203 \pm 3 \mathrm{mg} / \mathrm{g} \mathrm{E}$ \\
\hline & Optima & E condit & & \\
\hline & $t(\min )$ & $P(\mathrm{~W})$ & $S($ ethanol $\%, v / v$ ) & \\
\hline \multicolumn{5}{|c|}{ For each response variable } \\
\hline$Y_{1}$ & 28.4 & 456.0 & 22.7 & $69 \pm 1 \%(w / w)$ \\
\hline$Y_{2}$ & 9.3 & 217.8 & 71.1 & $27.8 \pm 0.4 \mathrm{mg} / \mathrm{g} \mathrm{E}$ \\
\hline$Y_{3}$ & 17.4 & 289.1 & 64.4 & $26.9 \pm 0.5 \mathrm{mg} / \mathrm{g} \mathrm{E}$ \\
\hline$Y_{4}$ & 19.8 & 274.9 & 76.2 & $48.0 \pm 0.5 \mathrm{mg} / \mathrm{g} \mathrm{E}$ \\
\hline$Y_{5}$ & 15.7 & 240.2 & 70.9 & $21.1 \pm 0.4 \mathrm{mg} / \mathrm{g} \mathrm{E}$ \\
\hline$Y_{6}$ & 19.1 & 184.8 & 76.0 & $26.7 \pm 0.5 \mathrm{mg} / \mathrm{g} \mathrm{E}$ \\
\hline$Y_{7}$ & 18.3 & 231.4 & 74.2 & $16.6 \pm 0.3 \mathrm{mg} / \mathrm{g} \mathrm{E}$ \\
\hline$Y_{8}$ & 18.8 & 208.6 & 77.0 & $10.9 \pm 0.2 \mathrm{mg} / \mathrm{g} \mathrm{E}$ \\
\hline$Y_{9}$ & 19.5 & 405.1 & 72.4 & $176 \pm 2 \mathrm{mg} / \mathrm{g} \mathrm{E}$ \\
\hline \multicolumn{5}{|c|}{ Considering all response variables } \\
\hline$Y_{1}$ & 18.7 & 327.4 & 69.3 & $53 \pm 1 \%(w / w)$ \\
\hline$Y_{9}$ & & & & $173 \pm 2 \mathrm{mg} / \mathrm{g} \mathrm{E}$ \\
\hline
\end{tabular}

Response variables: $\mathbf{Y}_{1}$ : extraction yield (extract weight); $\mathbf{Y}_{2}$ : tetragalloylglucoside II; $\boldsymbol{Y}_{\mathbf{3}}$ : tetragalloyl-glucoside III; $\boldsymbol{Y}_{\mathbf{4}}$ : pentagalloyl-glucoside; $\boldsymbol{Y}_{\mathbf{5}}$ : galloyl-bis-HHDP-glucose II; $\boldsymbol{Y}_{\mathbf{6}}$ : digalloyl-bis-HHDP-glucose II; $\boldsymbol{Y}_{\mathbf{7}}$ : trigalloylbis-HHDP-glucose I; $\boldsymbol{Y}_{\mathbf{8}}$ : trigalloyl-bis-HHDP-glucose II; and $\boldsymbol{Y}_{\mathbf{9}}$ : total tannins.

observed in the UAE process.

Although the linear effect of the solvent $(S)$ had the most significant impact on the responses for both extraction methods, the use of RSM was important because it allowed assessing the quadratic and interaction effects of the variables. Together, the parametric values of the different variables facilitate the determination of the optimum conditions for each response.

\subsection{HAE and UAE: Individual, global, and comparison of the two methods optimal conditions}

From the response surface graphs (Figs. 1 and 2), it is possible to infer that an optimal extraction value can be obtained as a single point in almost all combinations. Accordingly, the extraction conditions that lead to an absolute maximum were computed for both methods and are presented in Table 5. The optimal HAE conditions for tannin recovery were mainly characterised by longer extraction times (27.3 to $104 \mathrm{~min}$ ) and medium to high temperatures ( 44.1 to $83{ }^{\circ} \mathrm{C}$ ). Regarding the solvent, the recovery of tannins from $C$. hypocistis was favoured by higher ethanol percentages ( 65.9 to $98.8 \%, v / v$ ), which is easily perceived on the response surface graphs of Fig. 2. The optimal UAE conditions for tannin recovery were characterised by short extraction times (9.3 to $28.4 \mathrm{~min}$ ), medium to high ultrasound power (184.8 to $456 \mathrm{~W}$ ), and increased ethanol percentages $(64.4$ to $77 \%, v / v)$. Since the industrial sector is interested in natural extracts, it is important to optimise processes to obtain higher amounts of both extract weight and tannins using sustainable extraction methods. The global conditions that simultaneously maximise the extraction yield and the total tannins content were also determined by selecting "maximize" for these response variables and giving them equal "importance" in the Design-Expert analysis (Table 5). Based on this second optimisation step, 95.1 min processing at $46.4{ }^{\circ} \mathrm{C}$ with $74.3 \%$ ethanol $(v / v)$ and $18.7 \mathrm{~min}$ of sonication at $69.3 \mathrm{~W}$ using $69.3 \%$ ethanol $(v / v)$ were the optimal HAE and UAE conditions, respectively, that maximised the target response variables.

The HAE and UAE were compared to determine which method is the most suitable to facilitate tannin recovery. For intracellular extraction, UAE has shown some advantages over HAE [36], herein demonstrated by significantly shorter processing times. According to previous reports, acoustic cavitation promotes solvent penetration into the plant material and consequent release of compounds, enhancing mass transfer faster than when using temperature as intensification factor [36]. It is also interesting to note that, although the lower ethanol concentrations gave rise to higher extraction yields (possibly due to greater recovery of water-soluble carbohydrates), the highest levels of tannins were achieved using higher ethanol concentrations (Fig. 3). Therefore, the variable solvent effectively contributed to the selectivity of the extraction processes. These results are supported by those previously reported by Liang and colleagues [37], who optimised heat reflux and UAE methods to recover hydrolysable tannins from water caltrop (Trapa quadrispinosa) pericarps and also found UAE as a time and energy-saving method when compared to heat reflux. The high temperature in heat reflux led to compounds degradation, also verified in the present study for HAE (Fig. 3). The authors also reported ethanol/water mixtures $(60: 40, v / v)$ as preferable to other organic solvents.

\subsection{Experimental validation of the predictive models}

The global HAE and UAE conditions that maximise both the extraction yield and the recovery of tannins from $C$. hypocistis were experimentally tested to evaluate the predictive accuracy of the theoretical models. The experimental data for extraction yield and total tannins were in good agreement with the model-predicted values, as confirmed by the post-analysis verification performed using the DesignExpert software $(\alpha=0.05)$. The HAE and UAE processes yielded $54 \pm$ $1 \%$ and $52 \pm 2 \%$ of extract weight, values that did not differ significantly from the predicted $53 \pm 1 \%$ in both cases (Table 5). Furthermore, while each gram of extract obtained by HAE contained $200 \pm 4 \mathrm{mg}$ of total tannins, the UAE resulted in $178 \pm 8 \mathrm{mg}$ of target total tannins. The predictive capacity of the mathematical models was thus experimentally validated for these dependent variables. However, despite the good agreement for the extraction yields and total tannin contents obtained with the two extraction methods, the contents of some of the individual compounds were not within the model-predicted values, as shown in Table A.1 provided in the supplementary material.

\section{Conclusions}

The present study demonstrated the capacity of the tested methods to extract tannins from C. hypocistis successfully. HAE offered slightly higher response values but required a longer processing time than UAE (95.1 versus $18.7 \mathrm{~min}$, respectively). As intensification factor, HAE needed $46.4{ }^{\circ} \mathrm{C}$ and UAE, $327.4 \mathrm{~W}$. Both methods required high ethanol percentages, $74.3 \%$ and $69.3 \%$, respectively, to simultaneously maximise the extract weight and tannin content. Although the ethanol percentage was the most relevant variable in both extraction processes, all three tested independent variables $(t, T / P$, and $S$ ) induced significant effects on the analysed responses, justifying the use of RSM. The optimal conditions (individual and global) will be further compared on their bioactive properties since the bioactive effect of tannins is highly dependent on each compound concentration and the synergies established between molecules.

A solid/liquid ratio screening will also be of interest to improve the process profitability with minimal solvent consumption. Furthermore, to draw more conclusions regarding the eco-efficiency of the developed processes, it will be essential to determine the associated energy inputs/ costs. 

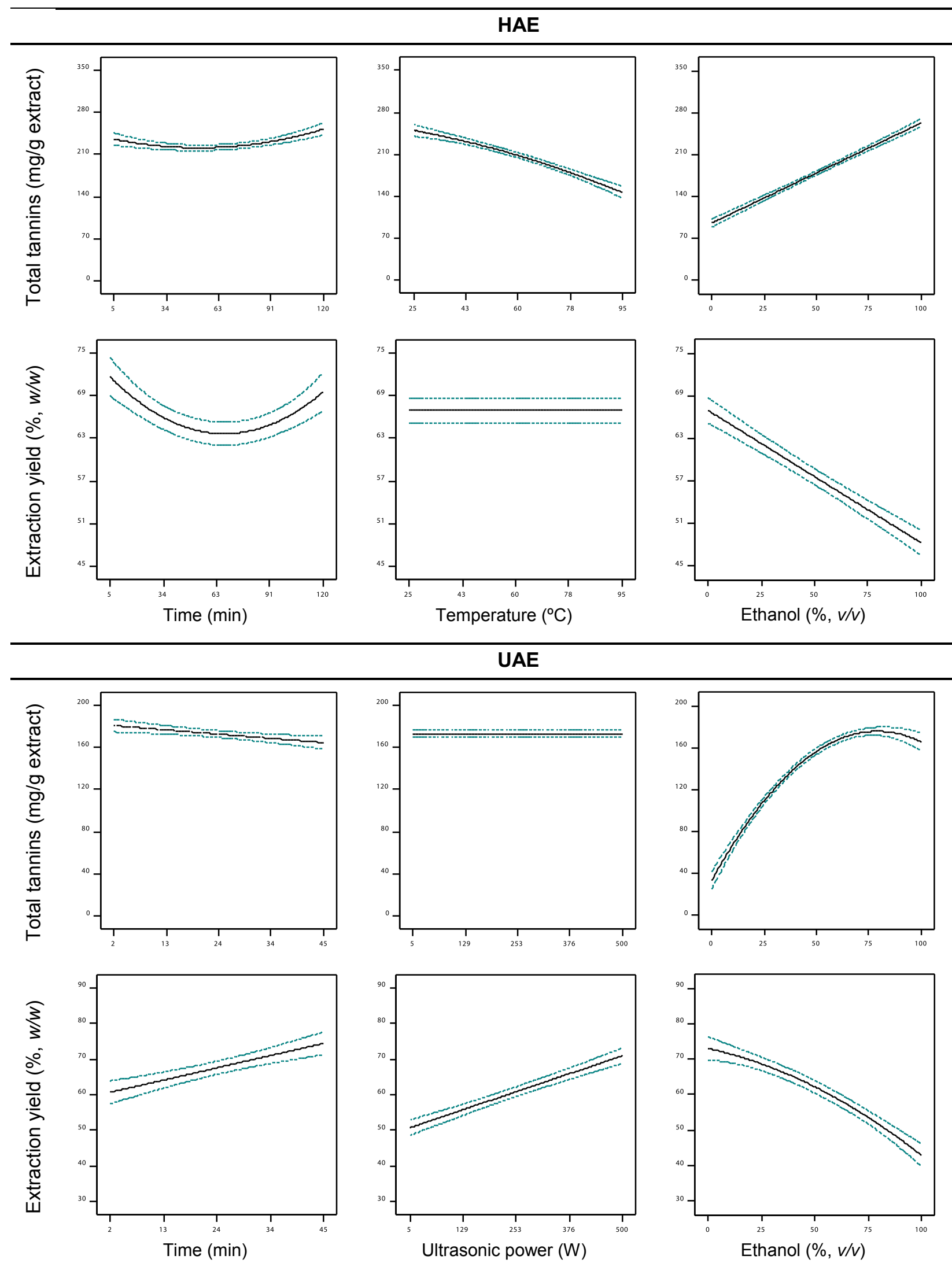

\section{UAE}
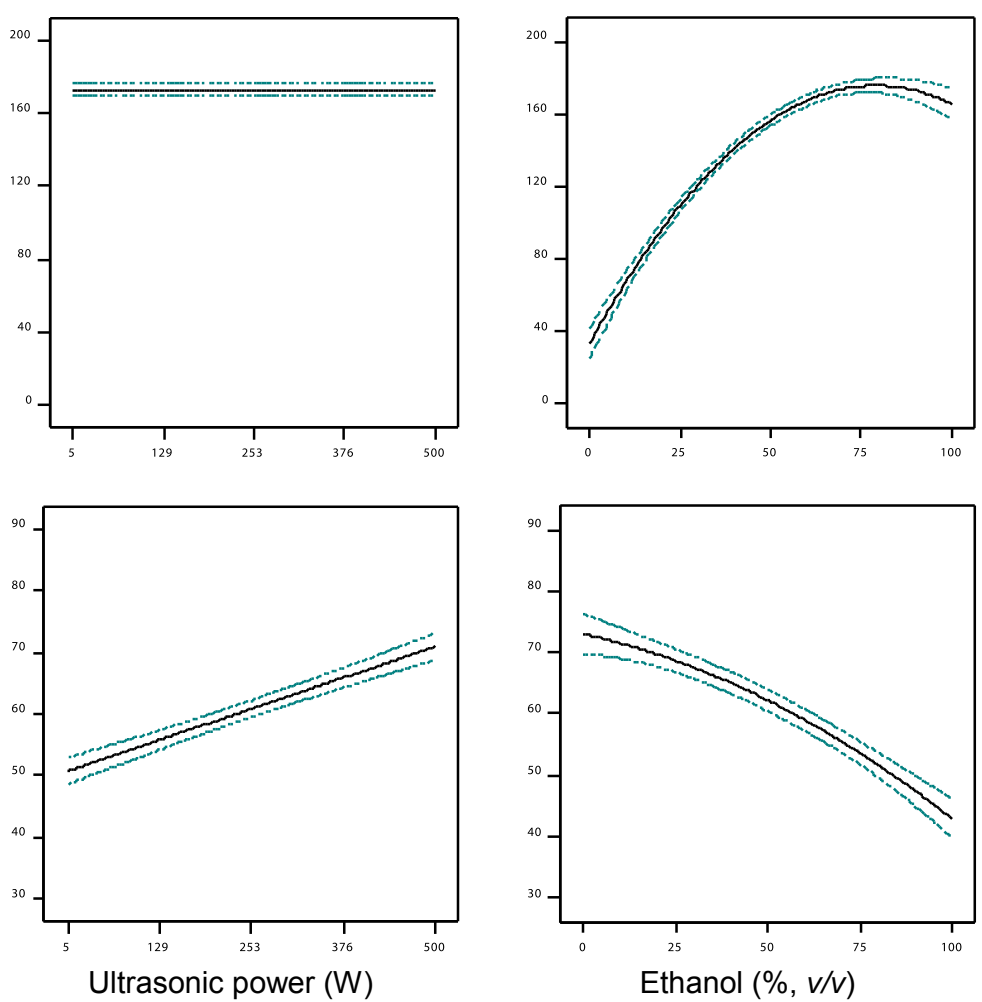

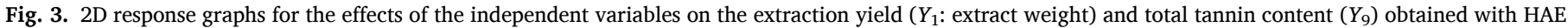
and UAE. In each graph, the excluded variables were fixed at their optimal value (Table 5). 


\section{Declaration of Competing Interest}

The authors declare that they have no known competing financial interests or personal relationships that could have appeared to influence the work reported in this paper.

\section{Acknowledgements}

The authors are grateful to the Foundation for Science and Technology (FCT, Portugal) for financial support through national funds FCT/MCTES to CIMO (UIDB/00690/2020). A. R. Silva is grateful to FCT and FSE for her Doctoral Grant (SFRH/BD/145834/2019), and J. Pinela and L. Barros for the contracts through the individual (CEECIND/ 01011/2018) and institutional scientific employment program-contract, respectively. The authors are also thankful to the FEDER-Interreg España-Portugal programme for financial support through the project TRANSCOLAB 0612_TRANS_CO_LAB_2_P and to ERDF through the Regional Operational Program North 2020, within the scope of the Project GreenHealth - Norte-01-0145-FEDER-000042.

\section{Appendix A. Supplementary material}

Supplementary data to this article can be found online at https://doi. org/10.1016/j.seppur.2021.119358.

\section{References}

[1] A. Arbenz, L. Avérous, Tannins: A Resource to Elaborate Aromatic and Biobased Polymers, in: Biodegrad. Biobased Polym. Environ. Biomed. Appl., John Wiley \& Sons, Inc., 2016: pp. 97-148. https://doi.org/10.1002/9781119117360.ch4.

[2] L. Falcão, M. Araújo, Vegetable tannins used in the manufacture of historic leathers, Molecules. 23 (5) (2018) 1081, https://doi.org/10.3390/ molecules23051081.

[3] A.K. Das, M.N. Islam, M.O. Faruk, M. Ashaduzzaman, R. Dungani, Review on tannins: Extraction processes, applications and possibilities, South African J. Bot. 135 (2020) 58-70, https://doi.org/10.1016/j.sajb.2020.08.008.

[4] K. Khanbabaee, T. van Ree, Tannins: Classification and definition, Nat. Prod. Rep. 18 (2001) 641-649, https://doi.org/10.1039/b1010611.

[5] Y. Shirmohammadli, D. Efhamisisi, A. Pizzi, Tannins as a sustainable raw material for green chemistry: A review, Ind. Crops Prod. 126 (2018) 316-332, https://doi. org/10.1016/j.indcrop.2018.10.034.

[6] K.P. Sharma, Tannin degradation by phytopathogen's tannase: A Plant's defense perspective, Biocatal. Agric. Biotechnol. 21 (2019) 101342, https://doi.org/ 10.1016/j.bcab.2019.101342.

[7] S. Morimoto, G. Nonaka, I. Nishioka, Tannins and Related Compounds. XXXVIII. 1) Isolation and characterization of flavan-3-ol glucosides and procyanidin oligomers from cassia bark (Cinnamomum cassia Blume), Chem. Pharm. Bull. 34 (1986) 633-642, https://doi.org/10.1248/cpb.34.633.

[8] Takashi Tanaka, Gen.-Ichiro. Nonaka, Itsuo Nishioka, Tannins and related compounds. XLII. Isolation and characterization of four new hydrolyzable tannins, terflavins A and B, tergallagin and tercatain from the leaves of Terminalia catappa $\mathrm{L}$, Chem. Pharm. Bull. (Tokyo). 34 (3) (1986) 1039-1049, https://doi.org/10.1248/ cpb.34.1039.

[9] Y. Kashiwada, G.-I. Nonaka, I. Nishioka, J.-J. Chang, K.-H. Lee, Antitumor agents, 129. Tannins and related compounds as selective cytotoxic agents, J. Nat. Prod. 55 (8) (1992) 1033-1043, https://doi.org/10.1021/np50086a002.

[10] J.P.F. D'Mello, J.H. Duffus, C.M. Duffus, Toxic substances in crop plants, Royal Society of Chemistry, Cambridge, 1991.

[11] D. Ferreira, R. Bekker, Oligomeric proanthocyanidins: Naturally occurring $O$ heterocycles, Nat. Prod. Rep. 13 (1996) 411-433, https://doi.org/10.1039/ np9961300411.

[12] M. Fraga-Corral, P. García-Oliveira, A.G. Pereira, C. Lourenço-Lopes, C. JimenezLopez, M.A. Prieto, J. Simal-Gandara, Technological application of tannin-based extracts, Molecules. 25 (2020) 614, https://doi.org/10.3390/molecules25030614.

[13] A.R. Silva, J. Pinela, M.I. Dias, R.C. Calhelha, M.J. Alves, A. Mocan, P.A. García, L. Barros, I.C.F.R. Ferreira, Exploring the phytochemical profile of Cytinus hypocistis (L.) L. as a source of health-promoting biomolecules behind its in vitro bioactive and enzyme inhibitory properties, Food Chem. Toxicol. 136 (2020) 111071, https://doi.org/10.1016/j.fct.2019.111071.

[14] B.R. Albuquerque, J. Pinela, L. Barros, M.B.P.P. Oliveira, I.C.F.R. Ferreira, Anthocyanin-rich extract of jabuticaba epicarp as a natural colorant: Optimization of heat- and ultrasound-assisted extractions and application in a bakery product, Food Chem. 316 (2020) 126364, https://doi.org/10.1016/j. foodchem.2020.126364.

[15] G. Rocchetti, F. Blasi, D. Montesano, S. Ghisoni, M.C. Marcotullio, S. Sabatini, L. Cossignani, L. Lucini, Impact of conventional/non-conventional extraction methods on the untargeted phenolic profile of Moringa oleifera leaves, Food Res. Int. 115 (2019) 319-327, https://doi.org/10.1016/j.foodres.2018.11.046.
[16] F.J. Barba, P. Putnik, D. Bursać Kovačević, M.M. Poojary, S. Roohinejad, J. M. Lorenzo, M. Koubaa, Impact of conventional and non-conventional processing on prickly pear (Opuntia spp.) and their derived products: From preservation of beverages to valorization of by-products, Trends Food Sci. Technol. 67 (2017) 260-270, https://doi.org/10.1016/j.tifs.2017.07.012.

[17] C. Castro-López, J.M. Ventura-Sobrevilla, M.D. González-Hernández, R. Rojas, J. A. Ascacio-Valdés, C.N. Aguilar, G.C.G. Martínez-Ávila, Impact of extraction techniques on antioxidant capacities and phytochemical composition of polyphenol-rich extracts, Food Chem. 237 (2017) 1139-1148.

[18] I. Mueller-Harvey, Analysis of hydrolysable tannins, Anim. Feed Sci. Technol. 91 (1-2) (2001) 3-20, https://doi.org/10.1016/S0377-8401(01)00227-9.

[19] T. Gomes, T. Delgado, A. Ferreira, J.A. Pereira, P. Baptista, S. Casal, E. Ramalhosa, Application of response surface methodology for obtaining lettuce (Lactuca sativa L.) by-products extracts with high antioxidative properties, Ind. Crops Prod. 44 (2013) 622-629, https://doi.org/10.1016/j.indcrop.2012.09.011.

[20] O. Taofiq, A.R. Silva, C. Costa, I. Ferreira, J. Nunes, M.A. Prieto, J. Simal-Gandara, L. Barros, I.C.F.R. Ferreira, Optimization of ergosterol extraction from: Pleurotus mushrooms using response surface methodology, Food Funct. 11 (7) (2020) 5887-5897, https://doi.org/10.1039/D0FO00301H.

[21] R. Rocha, J. Pinela, R.M.V. Abreu, M. Añibarro-Ortega, T.C.S.P. Pires, A. L. Saldanha, M.J. Alves, A. Nogueira, I.C.F.R. Ferreira, L. Barros, Extraction of Anthocyanins from red raspberry for natural food colorants development: processes optimization and in vitro bioactivity, Processes. 8 (2020) 1447, https:// doi.org/10.3390/pr8111447.

[22] P. Sahoo, T.K. Barman, ANN modelling of fractal dimension in machining, in, Mechatronics Manuf. Eng., Elsevier (2012) 159-226, https://doi.org/10.1533/ 9780857095893.159.

[23] A.R. Silva, Â. Fernandes, P.A. García, L. Barros, I.C.F.R. Ferreira, A.R. Silva, A. Fernandes, P.A. García, L. Barros, I.C.F.R. Ferreira, Cytinus hypocistis (L.) L subsp. macranthus Wettst.: Nutritional characterization, Molecules. 24 (2019) 1111.

[24] V. Vieira, M.A. Prieto, L. Barros, J.A.P. Coutinho, O. Ferreira, I.C.F.R. Ferreira, Optimization and comparison of maceration and microwave extraction systems for the production of phenolic compounds from Juglans regia L. for the valorization of walnut leaves, Ind. Crops Prod. 107 (2017) 341-352.

[25] JordanaN. Sousa, NathaliaB. Pedroso, LeonardoL. Borges, G. A., JoseR. Paula, EdemilsonC. Conceicao, Optimization of ultrasound-assisted extraction of polyphenols, tannins and epigallocatechin gallate from barks of Stryphnodendron adstringens (Mart.) Coville bark extracts, Pharmacogn. Mag. 10 (38) (2014) 318, https://doi.org/10.4103/0973-1296.133287.

[26] P.N. Diouf, T. Stevanovic, Y. Boutin, The effect of extraction process on polyphenol content, triterpene composition and bioactivity of yellow birch (Betula alleghaniensis Britton) extracts, Ind. Crops Prod. 30 (2) (2009) 297-303, https:// doi.org/10.1016/j.indcrop.2009.05.008.

[27] C. Carrera, A. Ruiz-Rodríguez, M. Palma, C.G. Barroso, Ultrasound assisted extraction of phenolic compounds from grapes, Anal. Chim. Acta. 732 (2012) 100-104, https://doi.org/10.1016/j.aca.2011.11.032.

[28] F. Dahmoune, G. Spigno, K. Moussi, H. Remini, A. Cherbal, K. Madani, Pistacia lentiscus leaves as a source of phenolic compounds: Microwave-assisted extraction optimized and compared with ultrasound-assisted and conventional solvent extraction, Ind. Crops Prod. 61 (2014) 31-40, https://doi.org/10.1016/j. indcrop.2014.06.035.

[29] F. Chemat, N. Rombaut, A. Meullemiestre, M. Turk, S. Perino, A.-S. Fabiano-Tixier, M. Abert-Vian, Review of green food processing techniques. Preservation, transformation, and extraction, Innov. Food Sci. Emerg. Technol. 41 (2017) 357-377, https://doi.org/10.1016/J.IFSET.2017.04.016.

[30] S.M.F. Bessada, J.C.M. Barreira, L. Barros, I.C.F.R. Ferreira, M.B.P.P. Oliveira, Phenolic profile and antioxidant activity of Coleostephus myconis (L.) Rchb.f.: An underexploited and highly disseminated species, Ind. Crops Prod. 89 (2016) 45-51, https://doi.org/10.1016/j.indcrop.2016.04.065.

[31] B.R. Albuquerque, M.A. Prieto, J.A. Vazquez, M.F. Barreiro, L. Barros, I.C.F. R. Ferreira, Recovery of bioactive compounds from Arbutus unedo L. fruits: Comparative optimization study of maceration/microwave/ultrasound extraction techniques, Food Res. Int. 109 (2018) 455-471, https://doi.org/10.1016/j. foodres.2018.04.061.

[32] M.G. Leichtweis, C. Pereira, M.A. Prieto, M.F. Barreiro, I.J. Beraldi, L. Barros, I.C.F. R. Ferreira, Ultrasound as a rapid and low-cost extraction procedure to obtain anthocyanin-based colorants from Prunus spinosa L. fruit epicarp: Comparative study with conventional heat-based extraction, Molecules. 24 (2019) 1-17.

[33] N. Iberahim, S. Sethupathi, C.L. Goh, M.J.K. Bashir, W. Ahmad, Optimization of activated palm oil sludge biochar preparation for sulphur dioxide adsorption, J. Environ. Manage. 248 (2019) 109302, https://doi.org/10.1016/j. jenvman.2019.109302.

[34] J. Pinela, M.A. Prieto, L. Barros, A.M. Carvalho, M.B.P.P. Oliveira, J.A. Saraiva, I.C. F.R. Ferreira, Cold extraction of phenolic compounds from watercress by high hydrostatic pressure: Process modelling and optimization, Sep. Purif. Technol. 192 (2018) 501-512.

[35] J. Pinela, M.A. Prieto, E. Pereira, I. Jabeur, M.F. Barreiro, L. Barros, I.C.F. R. Ferreira, Optimization of heat- and ultrasound-assisted extraction of anthocyanins from Hibiscus sabdariffa calyces for natural food colorants, Food Chem. 275 (2019) 309-321, https://doi.org/10.1016/j.foodchem.2018.09.118.

[36] J.F. Osorio-Tobón, Recent advances and comparisons of conventional and alternative extraction techniques of phenolic compounds, J. Food Sci. Technol. 57 (12) (2020) 4299-4315, https://doi.org/10.1007/s13197-020-04433-2.

[37] X. Liang, Y. Jiang, Z. Guo, S. Fang, Separation, UPLC-QTOF-MS/MS analysis, and antioxidant activity of hydrolyzable tannins from water caltrop (Trapa 
quadrispinosa) pericarps, LWT. 133 (2020) 110010, https://doi.org/10.1016/j. lwt.2020.110010. 